\title{
Features and allometric relationships characterising trees on farmland - an example from Chainpur VDC, Chitwan
}

\begin{abstract}
Henrik Meilby ${ }^{1}$ and Lila Puri ${ }^{2}$
Trees on farmland are important sources of fodder, food and a range of wood products and improve local climate and the ecological quality of agricultural landscapes. In spite of this, little is known about the composition of farm tree populations, farmer's management and the resulting characteristics of the trees. In a case study in Chainpur VDC, Chitwan, all trees with diameter ${ }^{3} 2 \mathrm{~cm} 0.5$ metres above ground were enumerated and mapped within 8.44 ha of farmland. The total number of trees was 898 , corresponding to a density of $106 \mathrm{ha}^{-1}$. The basal area 0.5 and $1.3 \mathrm{~m}$ above ground were 2.00 and $1.42 \mathrm{~m}^{2} \mathrm{ha}^{-1}$, respectively, and the total crown cover was $8.76 \%$. The number of species recorded was 63 , most of which were represented by only a few individuals. The most frequent species were Melia azedarach L. (Bakaino, 238 individuals), Bauhinia purpurea Wall. (Tanki, 111 individuals) and Ficus hispida L.f. (Khasreto, 87 individuals). Measurements of diameter and height of crown and stem were done for a sample comprising $81 \%$ of the trees. In addition, ocular assessment of the lopping intensity was carried out. Based on these observations, a set of allometric models relating stem diameter, tree height, crown width, crown length and lopping were developed and used for preparation of schematic tree silhouettes. Marked differences between tree species were observed with regard to crown shape and the effect of lopping on shape.
\end{abstract}

Key words: allometric models, farmer's tree species preferences, fodder tree species, lopping assessment, tree silhouettes

I n Nepal, farmland without trees is difficult to imagine. Traditionally, farmers have planted and protected a number of trees within their private land and on available marginal lands. These trees act as a source of recurrent flows of food, fodder and other useful materials, help meeting contingency needs for tree products, and provide shade around houses. In addition, farm trees can be seen as a means of biodiversity conservation and carbon sequestration (Acharya 2006, Chamber et al. 1993, Pandey 2002).

Trees on farmland are subjected to continuous interventions. Simons et al. (2000) distinguished four types of such interventions: [1] replacement (when species A is felled and planted again), [2] substitution (when species A is felled and species B is planted), [3] expansion (when number of trees is increased through planting) and [4] management (taking care of existing trees through watering, fencing, pruning or lopping). People may increase or decrease the planting of a particular species or of trees in general depending on their perceived usefulness and/or the availability of planting sites. Through management interventions, farmers shape and rearrange trees in the landscape to suit their needs. These needs change over time and the response of the farmers changes accordingly (Gilmour et al. 1991).

Farm trees are managed in different ways depending on the main purpose for which they are grown. Trees mainly used as fodder trees are lopped, whereas trees with a potential for production of construction timber are pruned to improve bole quality. Generally, lopping and pruning decisions are made based on silvicultural characteristics of the tree species (growth rate, coppicing capability and natural crown and stem shape development), main products aimed at, age and size of the tree, and planting site (home garden/yard, roadside, along canals etc.). This implies that after reaching a certain size, farm trees are often tended to maintain crown size and shape. To accomplish this trees are lopped to a certain extent and in a certain way, influencing their growth, overall yield and the size distribution and composition of the yield with regard to branch wood, bark and foliage.

In order to increase the knowledge on benefits derived by farmers from trees on farmland the

\footnotetext{
${ }^{1}$ Associate Professor, University of Copenhagen, Faculty of Life Sciences, Copenhagen, email: heme@life.ku.dk

${ }^{2}$ Research Officer, ComForM, Institute of Forestry (IOF) / TU, Pokhara, email: puri07878@alumni.itc.nl
} 
ComForM project, a research capacity development programme implemented jointly by Institute of Forestry (IOF), Tribhuvan University, and Forest \& Landscape Denmark at the University of Copenhagen, is planning a general survey of trees on farmland at the project's long-term research sites, aiming to assess the yield and value of products from such trees. This paper presents some outcomes of a preliminary survey. The objectives of the paper are to (1) describe the current species composition and density of trees within the study area and (2) develop a set of allometric models describing local relationships between stem diameter, lopping intensity, tree height and measures of crown size.

\section{Materials and methods}

In January 2006 a preliminary survey was conducted in Chainpur VDC, Chitwan to investigate the spatial distribution, species composition and lopping practice of farm trees. Within a small area of 8.44 ha all trees with a stem diameter e" $2 \mathrm{~cm} 0.5$ metres above ground were enumerated and mapped (Figure 1). Trees located along roads, ditches, canals, between fields and, generally, forming linear landscape features or dense clusters close to such features (e.g. trees growing in home gardens) were positioned by measuring distances along and across a series of line segments established in the field. For individual trees growing in isolated positions UTM coordinates were recorded using a GPS instrument.

In a few cases plantings were so dense and homogeneous that measuring all individual trees was considered too time consuming in view of the information obtained and the area covered. In such cases it was decided to record the species for all individuals but to carry out measurements only for a systematic random sample including 20-25 per cent of the trees.

The total number of trees recorded within the study area was 898 . For all trees the species was recorded and for 728 trees $(81 \%)$ the following measurements were done: stem diameter 0.5 metres above ground, stem diameter 1.3 metres above ground (dbh), total height, bole length (height to the lowermost prominent branch or branch thicker than $10 \%$ of the main stem), crown width in two perpendicular directions, and lopping percentages (see below) with regard to the main branch structure and foliagecarrying branches. For bamboo the circumference of each clump was measured 0.5 metres above ground and the percentage of culms that had been harvested was recorded.

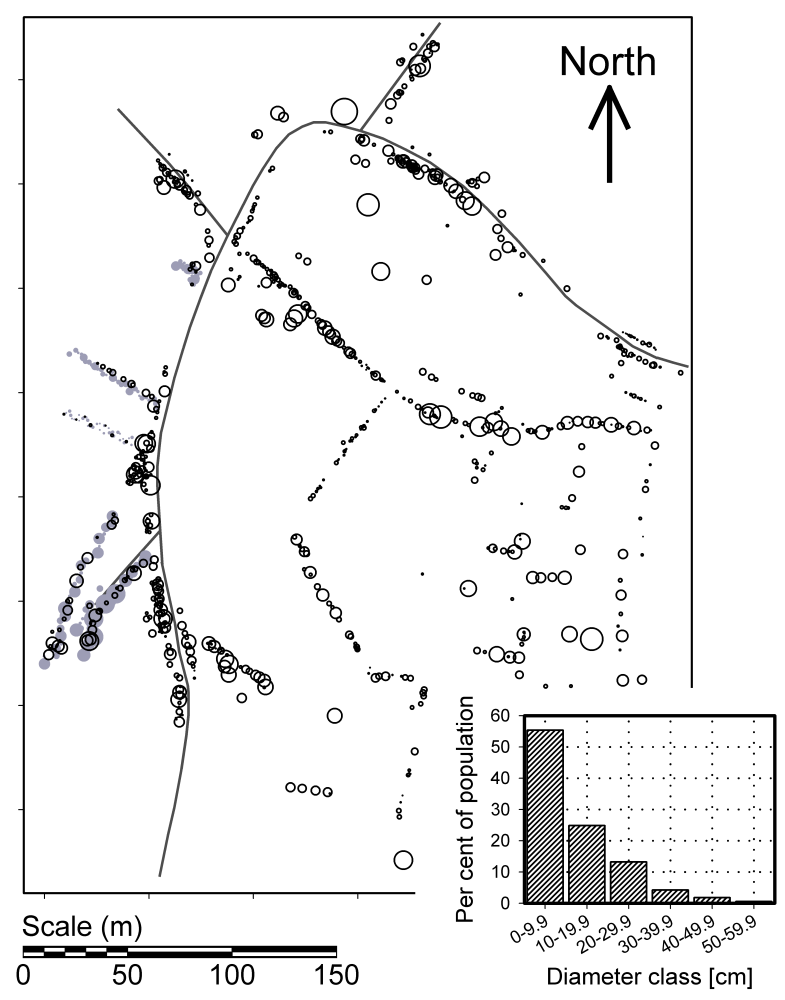

Figure 1: Stem map and diameter distribution for trees in the 8.44 ha sample area in Chainpur VDC. Roads are shown as unbroken lines. Diameter of circles is proportional to stem diameter $0.5 \mathrm{~m}$ above ground. Trees for which only the species was recorded are indicated by grey dots.

The intensity of lopping practices was assessed by visually judging the percentage of the overall crown structure (branches) and foliage that remained. Since the work was done in January, the assessment of foliage removal was in many cases based on foliagecarrying branches/twigs rather than foliage as such. An assessment of this type is inherently subjective and to limit the consequences of this we adopted the principle illustrated in Figure 2. Based on the present stem diameter and branching structure of the tree we tried to mentally reconstruct the natural expansion of branches and foliage and based on the resulting mental image we assessed the percentage of branches and foliage remaining, no matter whether these were part of the original crown or constituted a secondary crown formed as a consequence of lopping.

Out of the total number of species observed the 12 most abundant and, hence, important (fodder) species 


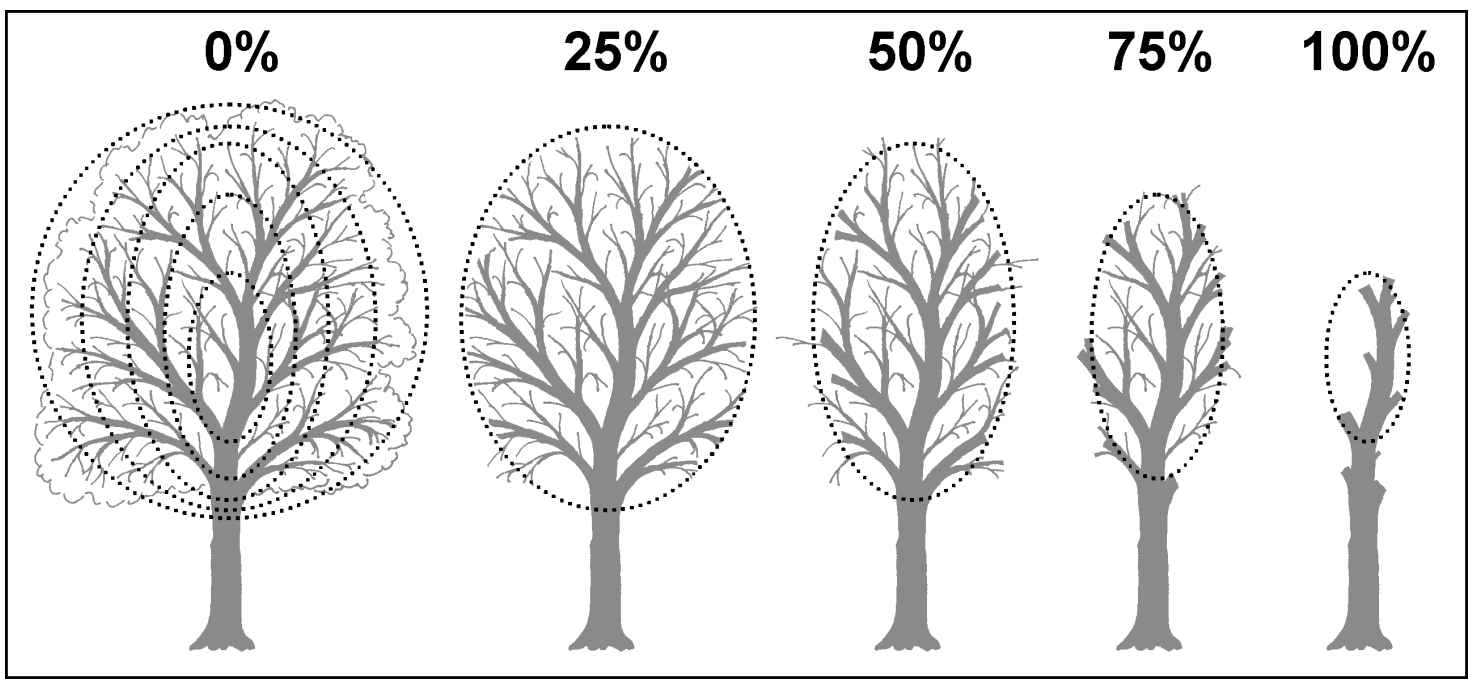

Figure 2: Lopping assessment approach. For any tree the percentage of the crown that seemed to be missing was judged by comparing with a hypothetical reference tree (left). The assessment was done for the main branching structure and for foliage-carrying branches.

were selected for a pilot preference survey. In this survey, which was conducted in January 2007, 13 farmers ranked the 12 species with regard to their perceived value for fodder, timber and fuelwood production and their cash income potential.

\section{Analysis}

In the analysis it was decided to distinguish between species that are used for fodder, species primarily grown for fruit production, and other species. The last of these categories includes species mainly used for timber. Furthermore, by forming species groups including some of the less abundant species we eliminated the problem that for some of the infrequent species the identification was presumably uncertain, particularly since the work was carried out in the dry season. Summary statistics were calculated for individual species and species groups.

For fodder species a set of regression models was developed to describe allometric relationships between the variables: diameter, lopping percentage, and total height, crown length, and crown width. Crown length was estimated as total height minus bole length. In the models the estimated lopping percentage with respect to branches was used. In all cases it was decided to model the relationships using allometric power models including modifications that account for the effects of lopping:

$Y_{i}=a+\left(b_{0}+b_{1} L_{i}\right) X_{i}^{c_{0}+c_{1} L_{i}}+\varepsilon_{i}$

and for differences between species:

$$
\begin{aligned}
Y_{i}=a+( & b_{0}+b_{1} L_{i}+d_{1} D_{i, s p 1}+\ldots \\
& \left.+d_{M} D_{i, s p M}\right) X_{i}^{c_{0}+c_{1} L_{i}}+\varepsilon_{i},
\end{aligned}
$$

where $Y_{i}$ is the observed value of the dependent variable, i.e. total height, crown height or crown width, for tree $i, X_{i}$ is either diameter 0.5 or 1.3 metres above ground, $L_{i}$ is lopping proportion $\left(0 £ L_{i} £ 1\right)$ with respect to branches, $D_{i, s p j}(j=1 \ldots M)$ are species dummies $\left(D_{i, s p}=1\right.$ if the tree belongs to species $j$, otherwise $\left.D_{i, p j}=0\right), a, b_{0}, b_{1}, c_{0}, c_{1}$, and $d_{1} \ldots d_{M}$ are model parameters and the $\mu_{i}$ are random errors which are assumed to be independently and normally distributed with mean zero and homogeneous variance. The model parameters were estimated using the procedure NLIN of the software package SAS ${ }^{\circledR}$ (v. 8.02).

\section{Results}

\section{Species composition and density}

Within the mapped area the total density of stems was $106 \mathrm{ha}^{-1}$. The basal area $0.5 \mathrm{~m}$ and $1.3 \mathrm{~m}$ above ground were $2.00 \mathrm{~m}^{2} \mathrm{ha}{ }^{-1}$ and $1.42 \mathrm{~m}^{2} \mathrm{ha}^{-1}$, respectively, and the total crown cover was 8.76 per cent. The total number of species recorded was 63 but many were characterised by a very low density: 19 species were represented by only one individual, 13 species by only two, and altogether 47 species by less than 10 individuals. The diameter distribution of trees was found to have a marked tail to the right and largediameter trees were scarce (cf. Figure 1). 
Summary statistics describing density of the tree vegetation and average tree size are shown in Table 1. The species are categorised as 'Fodder species', 'Fruit species' and 'Other species' and the table includes entries for 19 individual species and three residual groups: 'Other fodder (7 species)', 'Other fruit ( 9 species)' and 'Other species ( 28 species)'. The species listed individually in Table 1 are those that seemed to be comparatively important and could always be assumed correctly identified. Among species listed individually four are represented by less than 10 individuals per species but the other 15 species are more abundant (11-238 individuals). Out of the whole population, 26.5 per cent were Melia azedarach L. (Bakaino) followed by Baubinia purpurea Wall. (12.4\%, Tanki), Ficus hispida L.f. (9.7\%, Khasreto), Ficus lacor Buch.-Ham. (5.0\%, Kavro), Leucaena leuocephala (Lam.) de Wit (4.2\%, Ipil ipil), and Dalbergia sissoo Roxb. ex DC. (4.2\%, Sissoo). Among fruit trees Psidium guajava L. (3.0\%) and Mangifera indica L. $(2.9 \%)$ were the most common species.

Of the total basal area $0.5 \mathrm{~m}$ above ground, $M$. azedarach accounted for $25.2 \%$ followed by F. lacor $(13.6 \%)$ and $M$. indica (11.6\%). For fodder species altogether, the proportion of total basal area was $63.9 \%$ while for all fruit species it was $24.3 \%$. The crown cover percentages of fodder and fruit tree species were $46.7 \%$ and $24.5 \%$, respectively (Table 1). Accordingly, a major part of both basal area and crown cover was contributed by fodder and fruit tree species. It may be noted that because of lopping the percentage of total crown cover contributed by fodder species was considerably lower than the corresponding percentages of basal area and, particularly, stem number.

\section{Farmer's preferences}

The results of the preliminary preference survey can be summarised as follows. M. azedarach (Bakaino) was the most preferred species for fodder and firewood and was also deemed to hold the greatest potential for income generation. For construction timber, $D$. sissoo (Sissoo) was preferred to other species, including M. azedarach. In addition, D. sissoo was ranked second with regard to firewood production and overall income potential. Other highly ranked species were L. lencocephala (Ipil ipil, mainly for fodder), B. purpurea (Tanki, mainly for fodder and firewood), and F. lacor (Kavro, mainly with regard to construction timber and income potential).
Regarding planting sites, the farmers identified roadsides, home gardens/yards, fallow lands, and places along irrigation canals as most suitable for all trees species. However, the preferred site for fastgrowing fodder species was around the home yard, presumably because this implies easy access to cutting down branches and feeding them to the animals. Planting in irrigated lands was considered undesirable for all species. For fodder species, planting in seasonally irrigated or non-irrigated lands was preferred. Not surprisingly, the respondents preferred planting fruit trees in home gardens.

\section{Lopping, height and crown size}

The lopping of trees for fodder and firewood was widely practised in the study area. The degree and nature of the lopping, however, varied between species. Species categorised as fodder tree species were lopped most intensively while the crowns of fruit tree species were almost intact. Thus, for fodder species on average, the lopping percentages were $59.7 \%$ (branches) and $66.0 \%$ (foliage), while for fruit species they were only $15.6 \%$ and $13.7 \%$ (cf. Table 1). For other species the corresponding mean lopping percentages were $47.9 \%$ and $48.9 \%$. For $M$. azedarach (Bakaino) mean lopping percentages as high as $72.2 \%$ and $85.4 \%$ were observed. Considering the large contribution of this species to total basal area $(25.2 \%)$ it was clearly the most important fodder species.

Models describing the relationships between stem diameter 0.5 and $1.3 \mathrm{~m}$ above ground, lopping intensity (branches) and height, crown width and crown length were developed to describe the effect of lopping on the size and proportions of trees (Table 2). Figure 3 illustrates the nature of models predicting tree height and crown width. The figure includes models of a general nature (B1 and D1) and models including species effects (B2 and D2). The graphs clearly show that height and crown width of the trees were negatively related to lopping intensity, i.e. for a given stem diameter, predicted total height and crown width decreased with increasing lopping intensity. The reduction in crown width was more conspicuous than that of tree height. By contrast, crown length was not affected much by lopping intensities less than $50 \%$ but was reduced to about half when the lopping intensity reached $95-100 \%$. For some fodder species like F. hispida (Khasreto), Litsea monopetala (Roxb.) Pers. and Garuga pinnata Roxb., the reduction in height, crown width and crown length was considerably greater than for fodder trees in general. By contrast 
Table 1 Summary statistics for individual species and species groups. Standard errors are given in rounded parentheses, percentages are in square parentheses, and number of trees recorded with regard to species but not measured are in curly parentheses.

\begin{tabular}{|c|c|c|c|c|c|c|c|c|c|c|}
\hline & $\begin{array}{c}\text { No. } \\
\text { of } \\
\text { trees }\end{array}$ & $\begin{array}{c}\mathrm{N} \\
{\left[\mathrm{ha}^{-1}\right]}\end{array}$ & $\begin{array}{c}\mathrm{G}_{1.3} \\
{\left[\mathrm{~m}^{2} \mathrm{ha}^{-1}\right]}\end{array}$ & $\begin{array}{c}\text { Crown } \\
\text { cover } \\
{[\%]} \\
\end{array}$ & $\begin{array}{l}\mathrm{d}_{0.5} \\
{[\mathrm{~cm}]}\end{array}$ & $\begin{array}{l}\mathrm{d}_{1.3} \\
{[\mathrm{~cm}]}\end{array}$ & $\begin{array}{l}\mathrm{h}_{\text {total }} \\
{[\mathrm{m}]}\end{array}$ & $\begin{array}{c}\mathrm{h}_{\text {bole }} \\
{[\mathrm{m}]}\end{array}$ & $\begin{array}{c}\text { Lopping } \\
\text { (branch) } \\
{[\%]}\end{array}$ & $\begin{array}{c}\text { Lopping } \\
\text { (foliage) } \\
{[\%]}\end{array}$ \\
\hline \multicolumn{11}{|l|}{ Fodder species } \\
\hline Artocarpus & 17 & 2.13 & 0.033 & 0.11 & 12.5 & 12.3 & 5.2 & 1.3 & 47.1 & 52.9 \\
\hline lakoocha & $\{1\}$ & {$[2.0]$} & {$[2.4]$} & [1.2] & $(2.5)$ & (2.3) & $(0.6)$ & $(0.2)$ & $(7.8)$ & (9.4) \\
\hline \multirow[t]{2}{*}{ Baubinia purpurea } & 61 & 13.15 & 0.041 & 0.35 & 5.6 & 5.1 & 3.2 & 1.0 & 47.6 & 51.4 \\
\hline & $\{50\}$ & {$[12.4]$} & {$[2.9]$} & {$[4.0]$} & $(0.5)$ & $(0.6)$ & $(0.1)$ & $(0.1)$ & (4.1) & (4.1) \\
\hline \multirow[t]{2}{*}{ Dalbergia sissoo } & 37 & 4.50 & 0.042 & 0.26 & 10.9 & 9.5 & 5.4 & 1.3 & 50.9 & 48.5 \\
\hline & $\{1\}$ & {$[4.2]$} & {$[3.0]$} & [2.9] & (1.4) & (1.4) & $(0.6)$ & $(0.2)$ & $(5.7)$ & (5.7) \\
\hline \multirow[t]{2}{*}{ Ficus hispida } & 80 & 10.31 & 0.039 & 0.26 & 8.3 & 6.4 & 2.8 & 0.8 & 64.9 & 65.6 \\
\hline & $\{7\}$ & {$[9.7]$} & {$[2.8]$} & {$[3.0]$} & $(0.6)$ & 0.5 & $(0.1)$ & $(0.1)$ & $(2.9)$ & (3.0) \\
\hline \multirow[t]{2}{*}{ Ficus lacor } & 45 & 5.33 & 0.193 & 0.90 & 19.3 & 18.3 & 6.2 & 1.6 & 50.1 & 54.4 \\
\hline & $\{0\}$ & {$[5.0]$} & [13.6] & {$[10.3]$} & $(2.1)$ & $(2.1)$ & $(0.6)$ & $(0.1)$ & $(4.8)$ & (5.1) \\
\hline \multirow[t]{2}{*}{ Ficus racemosa } & 8 & 1.30 & 0.035 & 0.19 & 21.6 & 15.3 & 6.3 & 1.5 & 33.1 & 36.3 \\
\hline & $\{3\}$ & {$[1.2]$} & {$[2.4]$} & {$[2.2]$} & (5.3) & $(3.9)$ & (1.3) & $(0.2)$ & (8.9) & $(10.2)$ \\
\hline \multirow[t]{2}{*}{ Ficus semicordata } & 8 & 0.95 & 0.011 & 0.12 & 11.8 & 12.6 & 4.1 & 1.0 & 43.8 & 38.8 \\
\hline & $\{0\}$ & {$[0.9]$} & {$[0.8]$} & [1.4] & (3.1) & $(2.8)$ & $(0.8)$ & $(0.3)$ & $(13.5)$ & (11.7) \\
\hline \multirow[t]{2}{*}{ Garuga pinnata } & 18 & 2.25 & 0.030 & 0.08 & 12.4 & 11.5 & 4.6 & 1.2 & 56.7 & 60.3 \\
\hline & $\{1\}$ & {$[2.1]$} & {$[2.1]$} & {$[1.0]$} & $(1.5)$ & $(1.7)$ & $(0.5)$ & $(0.1)$ & (6.3) & (6.9) \\
\hline Leucaena & 35 & 4.50 & 0.028 & 0.12 & 8.0 & 7.3 & 4.6 & 1.7 & 61.0 & 62.9 \\
\hline \multirow{3}{*}{$\begin{array}{l}\text { leucocephala } \\
\text { Litsea monopetala }\end{array}$} & $\{3\}$ & {$[4.2]$} & {$[2.0]$} & {$[1.4]$} & (1.1) & $(1.0)$ & $(0.3)$ & $(0.1)$ & $(5.5)$ & (5.7) \\
\hline & 30 & 3.91 & 0.054 & 0.09 & 13.7 & 11.2 & 3.8 & 1.7 & 63.3 & 70.3 \\
\hline & $\{3\}$ & {$[3.7]$} & {$[3.8]$} & [1.1] & $(1.5)$ & $(1.4)$ & $(0.2)$ & $(0.1)$ & $(6.2)$ & $(6.8)$ \\
\hline \multirow[t]{2}{*}{ Melia azedarach } & 182 & 28.20 & 0.358 & 1.28 & 13.9 & 11.0 & 4.9 & 1.5 & 72.2 & 85.4 \\
\hline & $\{56\}$ & {$[26.5]$} & {$[25.2]$} & [14.6] & $(0.7)$ & $(0.5)$ & $(0.2)$ & $(0.1)$ & $(1.9)$ & (1.8) \\
\hline \multirow[t]{2}{*}{ Morus alba } & 15 & 1.90 & 0.007 & 0.09 & 7.1 & 6.3 & 3.9 & 0.8 & 34.7 & 40.3 \\
\hline & $\{1\}$ & {$[1.8]$} & {$[0.5]$} & {$[1.0]$} & $(1.3)$ & $(1.4)$ & $(0.4)$ & $(0.1)$ & (7.3) & $(9.6)$ \\
\hline Other fodder & 14 & 2.01 & 0.037 & 0.24 & 16.7 & 15.8 & 7.5 & 2.4 & 33.9 & 42.9 \\
\hline (7 species) & $\{3\}$ & {$[1.9]$} & {$[2.6]$} & {$[2.7]$} & $(2.7)$ & (2.1) & (1.1) & $(0.4)$ & (5.7) & (8.5) \\
\hline \multirow{2}{*}{ Fodder, all } & 550 & 80.45 & 0.908 & 4.09 & 11.9 & 10.2 & 4.5 & 1.3 & 59.7 & 66.0 \\
\hline & $\{129\}$ & {$[75.6]$} & [63.9] & {$[46.7]$} & $(0.4)$ & $(0.4)$ & $(0.1)$ & $(0.04)$ & (1.3) & (1.4) \\
\hline \multicolumn{11}{|l|}{ Fruit species } \\
\hline Artocarpus & 7 & 2.49 & 0.107 & 0.42 & 23.2 & 21.2 & 8.2 & 1.9 & 29.3 & 26.4 \\
\hline \multirow{3}{*}{$\begin{array}{l}\text { beterophyllus } \\
\text { Mangifera indica }\end{array}$} & $\{14\}$ & {$[2.3]$} & {$[7.6]$} & [4.8] & $(4.2)$ & $(4.1)$ & $(1.2)$ & $(0.2)$ & (8.8) & $(8.9)$ \\
\hline & 22 & 3.08 & 0.165 & 1.01 & 27.2 & 22.2 & 8.2 & 1.5 & 5.0 & 4.8 \\
\hline & $\{4\}$ & {$[2.9]$} & [11.6] & [11.6] & (3.3) & $(3.0)$ & $(0.7)$ & $(0.1)$ & (1.9) & $(2.0)$ \\
\hline \multirow[t]{2}{*}{ Psidium guajava } & 24 & 3.20 & 0.004 & 0.11 & 5.3 & 4.0 & 3.5 & 0.9 & 22.5 & 17.5 \\
\hline & $\{3\}$ & {$[3.0]$} & {$[0.3]$} & {$[1.2]$} & $(0.5)$ & $(0.3)$ & $(0.2)$ & $(0.1)$ & $(5.0)$ & $(4.2)$ \\
\hline Ziøyphus & 6 & 0.71 & 0.001 & 0.14 & 9.0 & 6.1 & 4.4 & 0.4 & 0.8 & 0.8 \\
\hline \multirow{2}{*}{$\begin{array}{l}\text { mauritiana } \\
\text { Other fruit }\end{array}$} & $\{0\}$ & {$[0.7]$} & {$[0.1]$} & [1.6] & (2.3) & $(0.9)$ & $(0.5)$ & $(0.1)$ & $(0.8)$ & $(0.8)$ \\
\hline & 17 & 2.61 & 0.068 & 0.46 & 16.2 & 14.3 & 6.9 & 1.5 & 19.1 & 19.1 \\
\hline (9 species) & $\{5\}$ & {$[2.4]$} & {$[4.8]$} & {$[5.3]$} & $(2.9)$ & $(2.8)$ & $(0.9)$ & $(0.2)$ & $(5.7)$ & (6.2) \\
\hline Fruit, all & 76 & 12.09 & 0.345 & 2.15 & 16.0 & 13.9 & 6.2 & 1.3 & 15.6 & 13.7 \\
\hline & $\{26\}$ & {$[11.4]$} & [24.3] & {$[24.5]$} & $(1.6)$ & $(1.5)$ & $(0.4)$ & $(0.1)$ & $(2.5)$ & $(2.3)$ \\
\hline Other specie & & & & & & & & & & \\
\hline Bombax ceiba & 6 & 0.71 & 0.059 & 0.41 & 23.7 & 26.8 & 11.5 & 6.0 & 1.7 & 1.7 \\
\hline & $\{0\}$ & {$[0.7]$} & {$[4.2]$} & [4.7] & $(7.2)$ & (8.3) & (2.8) & $(1.4)$ & (1.1) & (1.1) \\
\hline Ceiba pentandra & 6 & 0.71 & 0.024 & 0.11 & 24.9 & 20.5 & 7.6 & 1.7 & 50.0 & 51.7 \\
\hline & $\{0\}$ & {$[0.7]$} & {$[1.7]$} & {$[1.3]$} & $(1.5)$ & (1.1) & $(0.8)$ & $(0.3)$ & $(3.7)$ & (8.3) \\
\hline Dendrocalamus & 10 & 1.66 & - & 1.45 & - & - & 13.7 & - & $37.0^{\dagger}$ & $32.5^{\dagger}$ \\
\hline strictus & $\{4\}$ & [1.6] & & {$[16.5]$} & & & (1.7) & & $(11.7)$ & (19.4) \\
\hline Other & 80 & 10.78 & 0.084 & 0.55 & 10.7 & 9.0 & 4.0 & 1.2 & 52.7 & 53.2 \\
\hline (28 species) & $\{11\}$ & {$[10.1]$} & {$[5.9]$} & {$[6.2]$} & $(0.8)$ & $(0.9)$ & $(0.3)$ & $(0.1)$ & (4.1) & (4.1) \\
\hline Other species, all & 102 & 13.86 & 0.167 & 2.52 & 12.4 & 11.4 & 5.6 & 1.6 & 47.9 & 48.9 \\
\hline & $\{15\}$ & {$[13.0]$} & [11.8] & {$[28.8]$} & $(1.0)$ & $(1.2)$ & $(0.5)$ & $(0.2)$ & (3.6) & $(3.8)$ \\
\hline
\end{tabular}

${ }^{\dagger}$ Percentage of culms removed

the height and crown length of D. sissoo was not affected as much as other species, presumably reflecting that this species is mainly a timber species. Based on models describing total height, crown width and crown length (Table 2), the tree silhouettes in Figure 4 were prepared, illustrating the combined effects of species, breast height diameter and lopping intensity. As will appear, the crowns of D. sissoo trees 
Table 2 Estimated parameters of models describing relationships between (A,B) diameter, lopping and tree height, (C,D) diameter, lopping and crown width, (E,F) diameter, lopping and crown length. Models are expressed as $Y=a+\left(b_{0}+b_{1} L+d_{1} D_{s p 1}+\ldots d_{M} D_{s p M}\right) X^{c_{0}+c_{1} L}$. Standard errors are given in parentheses. Variables: $d_{0.5}:$ diameter 0.5 metres above ground $(\mathrm{cm}), d_{1.3}:$ diameter 1.3 metres above ground $(\mathrm{cm}), h:$ height $(\mathrm{m}), C W: \mathrm{crown}$ width (m), $C L$ : crown length (m), $L$ : Lopping proportion (branches), $D_{s p 1}, \ldots, D_{s p M}$ : species dummies.

\begin{tabular}{|c|c|c|c|c|c|c|c|c|c|c|}
\hline Model & $a$ & $b_{0}$ & $b_{1}$ & $d_{1}$ & $d_{2}$ & $d_{3}$ & $d_{4}$ & $d_{5}$ & $c_{0}$ & $c_{1}$ \\
\hline \multicolumn{4}{|c|}{ Model A: $Y=h, X=d_{0.5}$} & D. sissoo & F. bispida & L. leucocephala & L. monopetala & Other fodder & \multirow{3}{*}{$\begin{array}{c}0.559 \\
(0.033)\end{array}$} & \multirow{3}{*}{$\begin{array}{c}0.143 \\
(0.052)\end{array}$} \\
\hline A1 & 0.5 & 1.394 & -0.836 & \multirow[t]{2}{*}{-} & \multirow[t]{2}{*}{-} & \multirow[t]{2}{*}{-} & \multirow[t]{2}{*}{-} & \multirow[t]{2}{*}{-} & & \\
\hline $\mathrm{MSE}=2.16$ & - & $(0.11)$ & $(0.14)$ & & & & & & & \\
\hline A2 & 0.5 & 1.184 & -0.402 & 0.308 & -0.276 & 0.230 & -0.261 & 0.327 & 0.618 & ns \\
\hline MSE $=1.69$ & - & $(0.072)$ & $(0.049)$ & $(0.052)$ & $(0.047)$ & $(0.060)$ & $(0.051)$ & $(0.067)$ & $(0.019)$ & \\
\hline \multicolumn{4}{|c|}{ Model B: $Y=h, X=d_{1.3}$} & D. sissoo & F. bispida & L. leucocephala & L. monopetala & Other fodder & \multirow{3}{*}{$\begin{array}{c}0.637 \\
(0.037)\end{array}$} & \multirow{3}{*}{$\begin{array}{c}0.150 \\
(0.061)\end{array}$} \\
\hline B1 & 1.3 & 1.128 & -0.720 & \multirow[t]{2}{*}{-} & \multirow[t]{2}{*}{-} & \multirow[t]{2}{*}{-} & \multirow[t]{2}{*}{ - } & \multirow[t]{2}{*}{-} & & \\
\hline MSE $=2.07$ & - & $(0.099)$ & $(0.12)$ & & & & & & & \\
\hline B2 & 1.3 & 0.978 & -0.374 & 0.341 & -0.275 & 0.170 & -0.234 & 0.320 & 0.687 & \multirow[t]{2}{*}{ ns } \\
\hline MSE $=1.56$ & - & $(0.067)$ & $(0.047)$ & $(0.051)$ & $(0.048)$ & $(0.055)$ & $(0.046)$ & $(0.061)$ & $(0.021)$ & \\
\hline \multicolumn{4}{|c|}{ Model C: $Y=C W, X=d_{0.5}$} & F. bispida & F. lacor & G. pinnata & L. monopetala & M. azedarach & \multirow{3}{*}{$\begin{array}{c}0.778 \\
(0.056)\end{array}$} & \multirow{3}{*}{ ns } \\
\hline C1 & 0.430 & 0.444 & -0.302 & \multirow[t]{2}{*}{-} & \multirow[t]{2}{*}{ - } & \multirow[t]{2}{*}{-} & \multirow[t]{2}{*}{-} & \multirow[t]{2}{*}{-} & & \\
\hline $\mathrm{MSE}=0.64$ & $(0.15)$ & $(0.090)$ & $(0.054)$ & & & & & & & \\
\hline C2 & ns & 0.785 & -0.409 & -0.0526 & 0.0911 & -0.114 & -0.202 & -0.0650 & 0.615 & ns \\
\hline MSE $=0.55$ & & $(0.47)$ & $(0.035)$ & $(0.027)$ & $(0.026)$ & $(0.039)$ & $(0.032)$ & $(0.018)$ & $(0.020)$ & \\
\hline \multicolumn{3}{|c|}{ Model D: $Y=C W, X=d_{1.3}$} & & F. lacor & G. pinnata & L. monopetala & \multirow[b]{2}{*}{ - } & \multirow[b]{2}{*}{ - } & \multirow[b]{2}{*}{$\begin{array}{c}0.598 \\
(0.021)\end{array}$} & \\
\hline $\begin{array}{l}\text { D1 } \\
\text { MSE }=0.71\end{array}$ & ns & $\begin{array}{l}0.953 \\
(0.059)\end{array}$ & $\begin{array}{l}-0.595 \\
(0.048)\end{array}$ & - & - & - & & & & ns \\
\hline D2 & ns & 1.028 & -0.612 & 0.152 & -0.148 & -0.198 & - & - & 0.557 & ns \\
\hline $\mathrm{MSE}=0.62$ & & $(0.060)$ & $(0.048)$ & (0.035) & $(0.050)$ & $(0.041)$ & & & $(0.021)$ & \\
\hline Model E: & $=C$ & $Y=d_{0.5}$ & & D. sissoo & F. bispida & L. monopetala & & & & \\
\hline E1 & 0.911 & 0.503 & -0.438 & - & - & - & - & - & 0.747 & 0.360 \\
\hline MSE $=1.78$ & $(0.20)$ & $(0.12)$ & (0.098) & & & & & & $(0.064)$ & $(0.050)$ \\
\hline E2 & 0.858 & 0.533 & -0.425 & 0.106 & -0.0862 & -0.0994 & - & - & 0.746 & 0.289 \\
\hline $\mathrm{MSE}=1.54$ & (0.19) & $(0.12)$ & (0.088) & $(0.028)$ & $(0.024)$ & $(0.028)$ & & & $(0.059)$ & $(0.048)$ \\
\hline Model F: & $=C$ & $Y=d_{1.3}$ & & D. sissoo & F. hispida & L. monopetala & & & & \\
\hline F1 & 0.996 & 0.634 & -0.543 & - & - & - & - & - & 0.724 & 0.330 \\
\hline MSE $=1.95$ & $(0.22)$ & $(0.15)$ & $(0.12)$ & & & & & & (0.064) & $(0.061)$ \\
\hline F2 & 0.927 & 0.684 & -0.527 & 0.156 & -0.117 & -0.140 & - & - & 0.720 & 0.244 \\
\hline MSE $=1.71$ & $(0.22)$ & $(0.15)$ & $(0.11)$ & $(0.041)$ & $(0.035)$ & $(0.040)$ & & & $(0.059)$ & $(0.058)$ \\
\hline
\end{tabular}
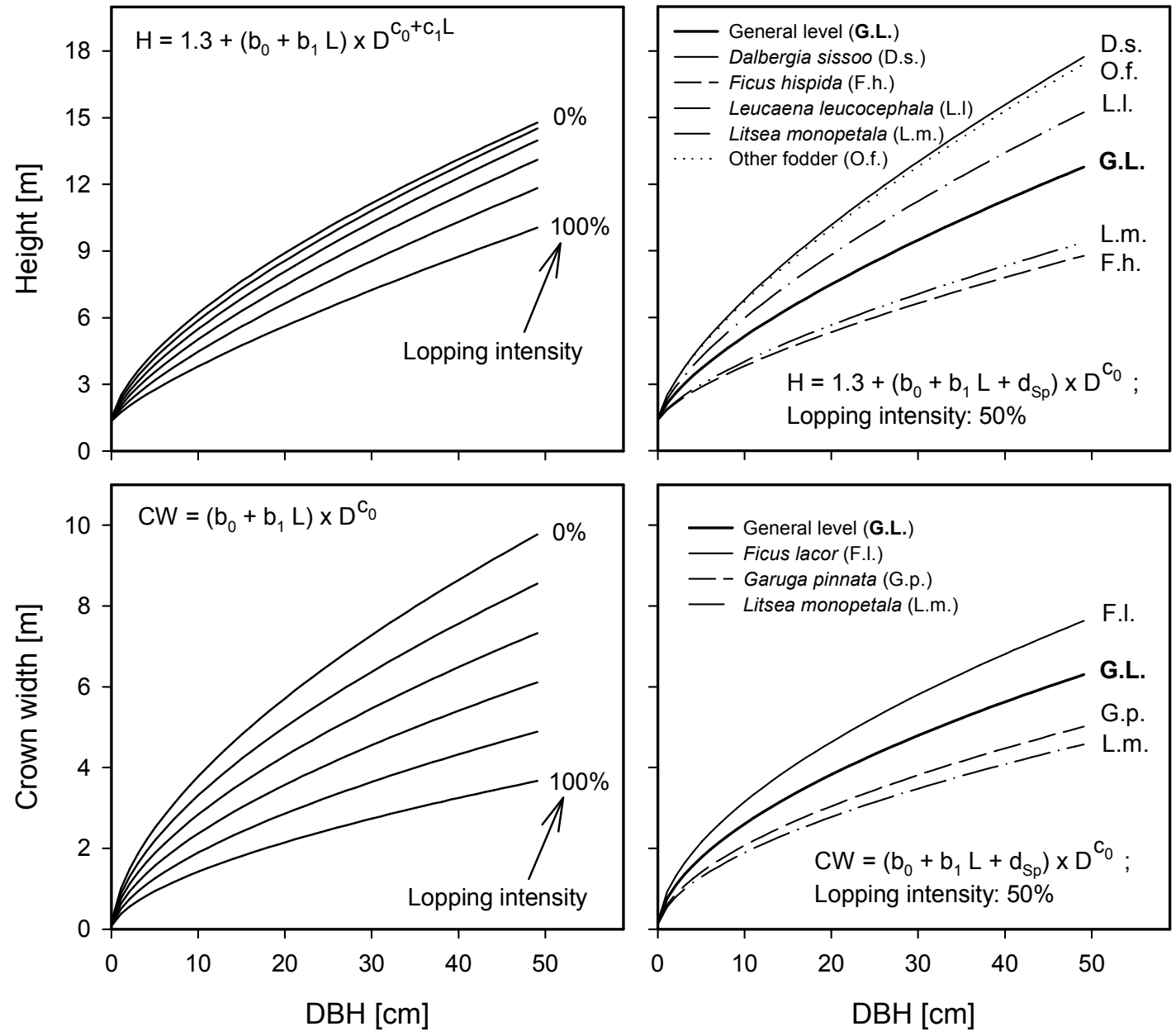

Figure 3: Predicted tree height (top) and crown width (bottom) as a function of breast height diameter. Left: for lopping intensities from 0 to 100\% (Models B1 and D1). Right: for different tree species (Models B2 and D2) at a lopping intensity of $50 \%$ (cf. Table 2 ). 


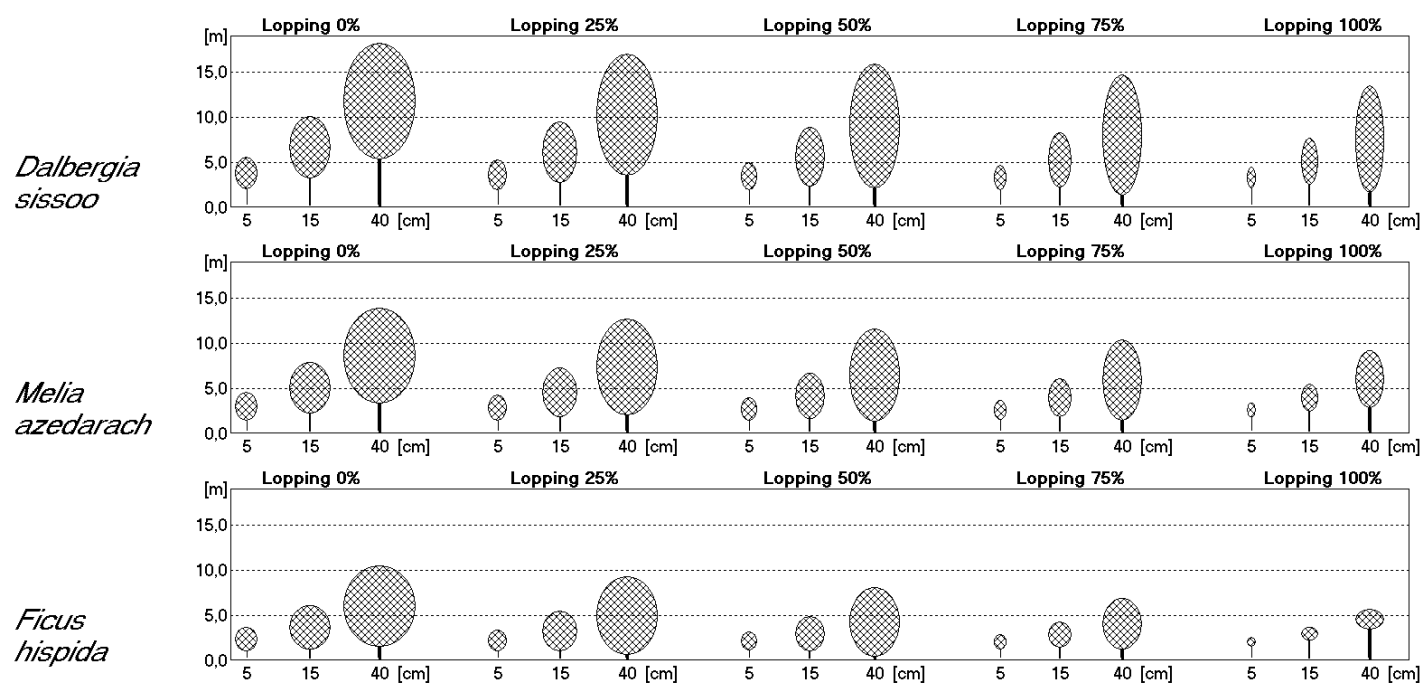

Figure 4 : Variation of tree proportions for selected tree species, depending on diameter at breast height and branch lopping intensity (percentage). Based on Models B2, D2 and F2 (cf. Table 2).

become more slender with increasing lopping intensity, whereas the crowns of more important fodder species, such as $M$. azedarach, become considerably shorter. The species F. hispida, which was ranked as a mediocre fodder species in the preference ranking exercise and was not considered useful for anything else, appears to be lopped from all sides.

In Models C1, C2, D1 and D2 the $c_{1}$ parameter was not significant (Table 2). Therefore, crown width is a linear function of lopping intensity (see also Figure 3, bottom left). By contrast, in Models E1, E2, F1 and F2 the $c_{1}$ parameter was significant and it is therefore difficult to describe exactly how our lopping intensity measure is related to crown profile area or volume. This was examined as follows. Assuming that the ellipsoidal crown shape used in Figure 4 is a meaningful generalisation of crown shape, crown profile area and crown volume were estimated as for an ellipsoid for different species and stem diameters. This was done for the whole range of lopping intensities $(0-100 \%)$ using models predicting crown width (D2) and crown length (F2). Next the crown profile area or volume estimated for a given lopping intensity was divided by the corresponding values for an unlopped tree and plotted against lopping intensity (not shown here). Based on these graphs it appeared that the estimated remaining crown profile area was in most cases somewhat greater, and the crown volume somewhat smaller, than expected in the ideal linear case. Consequently, it appears that the applied assessment principle provides a lopping intensity measure that is linearly related to crown width and constitutes a reasonable compromise between ideal linear measures of the effect of lopping on crown profile area and crown volume.

\section{Discussion}

In the study area the species composition was dominated by fast-growing multipurpose (fodder) and fruit tree species. The comparatively large number of species indicated that rural people traditionally plant and use a wide range of tree species for sustaining their livelihoods and agricultural production systems. For comparison Das and Oli (2001) observed 25 tree species (i.e. less than half of the number recorded in this study) in private farmlands of Birendranagar VDC (Chitwan), which borders on Chainpur, and concluded that compared with Sunsari (eastern Terai) and Kanchanpur (farwestern Terai), Chitwan was characterised by a greater species richness. They further reported that since disease started to spread in D. sissoo plantations (the sissoo decline) farmers increasingly replaced $D$. Sissoo with other fast-growing multipurpose trees. In Chitwan they mentioned M. azedarach (Bakaino) as a popular alternative to D. sissoo. In the present study, $M$. azedarach was the most abundant tree species. Furthermore, $M$. azedarach was preferred by farmers for fodder, fuelwood, and construction timber and was considered to hold the greatest cash income potential. Another popular species in the study area was B. purpurea (Tanki). Results on the canopy biomass production and possible genetic improvement of this species were reported recently by Jha et al. (2006) based on data from a Breeding Seed Orchard at Teel Kane (Chitwan).

Road sides, canal sides, field boundaries and homesteads were the most popular places for tree planting. Because of the great importance of irrigated 
lands for agricultural crop production, farmers generally avoided tree planting on such lands and, therefore, only a few scattered trees were observed in irrigated lands. For reasons of protection economically valuable species like fruit trees and bamboo tended to cluster around home yards and in gardens.

The allometric models showed that the applied lopping pattern and its effect on crown size and shape depended on tree species. This can be interpreted as a consequence of the natural growth habits of the species in combination with their different roles and uses. However, whether the applied lopping intensities and patterns lead to the greatest possible yield and highest possible quality of fodder is an important matter that cannot be assessed based on the present dataset. An experiment carried out in Rajasthan, India, revealed that the degree of lopping had no significant effects on year-to-year height and diameter growth and fodder yield. However, although not statistically significant, the mean annual diameter increment percentage was generally lowest in the case of complete crown lopping (Kumar et al. 2000). Similarly, in an experiment with Tectona grandis L.f., Viquez et al. (2005) reported that the cumulative growth (diameter or volume) of trees that were severely pruned at an early age was likely to remain lower than that of unpruned trees.

The lopping intensity was assessed visually by judging the apparent reduction of the crowns in terms of foliage and larger branches. Allometric models indicated that these inherently subjective estimates are linearly related to crown width. In addition, by modelling tree crowns as ellipsoids and comparing crown profile areas and volumes of lopped trees with those of undisturbed tree crowns it was found that our assessment technique appears to form a compromise between assessing the percentage reduction of crown profile area and crown volume. To test the practical reliability of the assessment technique we tried comparing our immediate visual estimates with estimates derived for the same trees by mentally dividing each tree crown into a number of components and doing an assessment for each of these. Afterwards a compounded lopping intensity estimate was calculated and weighted by the stem crosssectional area at the base of each crown component. This test was carried out for a small sample of 16 trees and showed that the two ways of assessing lopping intensity yielded consistent results. As the assessment of each crown component was based on foliage loss, the compounded result compared best with the foliage loss assessment of the tree. In this case the coefficient of determination $\left(\mathrm{R}^{2}\right)$ of a regression of simple lopping intensity estimates on compounded estimates was as high as 0.88 .

\section{Conclusion}

The farm tree population included a considerable number of species but for most species the number of individuals was low and a large proportion of basal area and crown cover was contributed by only a few fodder species preferred by the farmers.

The applied ocular assessment of lopping intensity appeared to be quite reliable, linearly related to crown width, and form a compromise between ideal measures of crown profile area and crown volume. Future work should investigate relationships between apparent lopping intensity and biomass, growth and fodder yield.

\section{Acknowledgements}

We gratefully acknowledge the contributions of faculty members of the Institute of Forestry who participated in the five-day survey forming the basis of this study. We would also like to express our sincere thanks to Sanjeeb Bhattarai, who assisted in field work and data entry, and Arun Rijal who helped us with species identification. Finally, we are deeply indebted to our local assistants and the community of Kankali whose kindness and support made this study possible. The ComForM programme is supported by the Danish Development Agency (Danida).

\section{References}

Acharya, K. P. (2006). Linking trees on farms with biodiversity conservation in subsistence farming systems in Nepal. Biodiversity and Conservation 15: 631-646.

Chambers R.; Leach M; Conroy C (1993). Tree as saving and security for rural poor, Gatekeeper series No. 3, International Institute for Environment and Development, London. 13 pp. URL: http:// www.iied.org/NR/agbioliv/gatekeepers/ documents/GK3.pdf (accessed 1 March 2007).

Das, A. N., Oli, B. N. (2001): Tree growing practices on farmlands: an option for sustaining rural livelihoods. Banko Janakari 11(2): 8-12.

Gilmour, G. A., Nurse, M. C. (1991). Farmer initiatives in increasing tree cover in central Nepal. Mountain Research and Development 11(4): 329-337.

Jha, P. K., Dhakal, L. P., Kjær, E. D., Lillesø, J. P. B. (2006): Improving productivity of Baubinia purpurea for tree planting farmers in Nepal. Agroforestry Systems 67: 273-278. 
Kumar, V. S. K., Tewari, V. P. (2000). Effect of lopping on the top feed production and growth of Prosopis cineraria. Bioresource Technology 74(2): 165-168.

Pandey, D. N. (2002). Carbon Sequestration in Agroforestry Systems, Climate Policy 2: 367-377.

Simons, A. J., Jaenicke, H., Tchoundjeu, Z., Dawson, I., Kindt, R., Oginosako, Z., Lengkeek, A.,
Grande, A. De (2000). The future of trees is on farms: Tree domestication in Africa, Sub-plenary papers and abstracts XXI IUFRO World congress 7-12 August, Kuala Lumpur, Malaysia.

Víquez, E., Pérez, D. (2005). Effect of pruning on tree growth, yield, and wood properties of Tectona grandis plantations in Costa Rica. Silva Fennica 39(3): 381-390. 